\title{
Prevalance of low back pain among nurses in Koshi Zonal Hospital, Biratnagar, Nepal
}

\author{
Dipty Subba $^{1 *}$, Neela Subba ${ }^{2}$, Lata Chaudhary ${ }^{3}$, Swasti Dev $^{3}$ \\ ${ }^{1}$ PUCMAS, Gothgaun, Morang, Nepal \\ ${ }^{2}$ Nursing Campus, TUIOM, Biratnagar, Nepal \\ ${ }^{3}$ Surgical Ward, Koshi Zonal Hospital, Biratnagar, Nepal \\ *Email:diptysubba@yahoo.com
}

\begin{abstract}
This small scale study on prevalence of low back pain among 50 nurses was done at selected different wards of Koshi zonal hospital. The main objective of this study was to determine the prevalence of low back pain among nurses. Nurses were included by convenient purposive sampling technique. Semistructure questionnaire with both close and open ended question was used for data collection. The findings of the study show that $56 \%$ had complain of low back pain and among them nurses working in operation theatre and orthopedics ward was more $(21 \%)$ prevalent. $38 \%$ of the respondents were staff nurse, $58 \%$ were married and $38 \%$ had more than 11 years of working experience as a registered nurse. Most (52\%) of the nurses mentioned that back pain was developed after joining the hospital duty or was related to work and among them $4 \%$ had taken medical leave. The most frequent contributing factors identified by the respondents were lifting, transferring of patients, staff shortage and heavy work load.
\end{abstract}

Key words: Low back pain, nurses, workload

\section{Introduction}

Low back pain (LBP) among nurses had been well known occupational health problem. LBP perhaps, more accurately called lumbago or lumbosacral pain occurs below the $12^{\text {th }}$ rib and above the gluteal folds. Occupational back pain (OBPN) constitutes a major source of morbidity in health care environment. Nurse is required to lift and transport patients or equipments, often in difficult environment. Describing the extent of musculoskeletal injury among nurses, survey showed that nurse lost 750,000 days a result day a year due to LBP (Sikiru \& Shmaila, 2009). Mechanical hazards in the hospital include LBP from manual lifting of patient which makes nursing most affected profession by LBP. Particularly in developing nation like Nepal where lifting aids are not always available or practicable. Hospital workers experience more low back pain than other groups, the incidence varies among countries. Work activities involving bending, twisting frequent, heavy lifting, awkward static posture and psychological stress are regarded as causal factors for many back injuries (Rahman, 2008).

\section{Materials and Methods}

This was a hospital based cross sectional study carried out at different wards of Koshi Zonal Hospital, Biratnagar. A total of 50 nurses employed at the hospital in maternity, Intensive Care Unit, operation theatre, paediatric, orthopedic, medical and surgical ward were enrolled by convenient purposive sampling in this study. Nurses who had less than 6 months experience, less than 20 years of age and who had been diagnosed with musculoskeletal disorder were excluded from the study. Semi-structure questionnaire consists of demographic variable and question related to back pain with both close and open ended question was used for data collection. 


\section{Results and Discussion}

The study was conducted to determine the prevalence of LBP among nurses working in Koshi Zonal Hospital, Biratnagar. Majority were staff nurse (38\%). Larger proportions (60\%) were between 20 to 30 years of age group, were married (58\%), but didn't have any children (96\%). Majority (38\%) had experience of more than 11 years and most of them were working in the current ward for less than two years $(32 \%)$.

The prevalence of LBP in this study was $56 \%$, which is lower than the findings of the study in a rural hospital (Rahmah, 2008) and higher (Yinbing, 2001). The relationship between designations, age, years in nursing was also seen. Senior nurses between the ages (30-49 years) had the highest prevalence of LBP $(39.28 \%)$ which is comparable to the findings among the nurses in Singapore General Hospital (Smedley et al., 2003). It can be concluded that junior nurses are more prone to develop LBP; possibly, they are involved in annual work, while the senior staff are assuming more organizational and managerial roles. Another possible reason could be that these junior nurses are less knowledgeable in proper lifting techniques and body mechanics. But, on the other hand, the study also suggests that nurses have good knowledge on lifting techniques and body mechanics (Vidya et al., 2014).

As nurses have to provide care round the clock, they are more at risk to develop LBP. Because there is an established association between shifts working and musculoskeletal symptoms and are more prevalent in shift workers than day workers (Attarchi et al., 2014).

Regarding the duty shift and the problem of LBP, in this study, more (68\%) nurses complained of the back pain in the night shift. The reasons identified by the respondents were due to inadequate nurse patient ratio, long duty hours as compared to other shift, and too many workloads.

The prevalence of LBP is expected to be higher among nurses in orthopedic wards and operation theatre than in other wards. Nursing working in orthopedic wards and operation theatre may be more involved in physical lifting and transferring of patients due to the nature of injuries or the condition of the patient (Yassi et al., 1995). Results showed that the highest percentage of LBP complaints was among nurses working in the operation theatre and orthopedics ward (21\%), followed by ICU (18\%), and the least percentage was in the surgical ward (7\%). Figure 1 provides a more detailed breakdown of the sources. These results could be explained on the basis that operation theatre and orthopedics wards are highly demanding departments where nurses sometimes have to take care of unambulatory patients. This is in discordance with the study by (Amany et al., 2014) who recorded that 87.0 and $75.0 \%$ of nurses working in the ICU and surgical departments, respectively, complained of LBP.

The most affected site of back pain as identified by nurses was the lumbo-sacral region, which is not surprising. This subjects the lumbo sacral (L4, L5, S1) to the greatest mechanical stress, compression, bio-mechanical strain and manual handling of patients. 


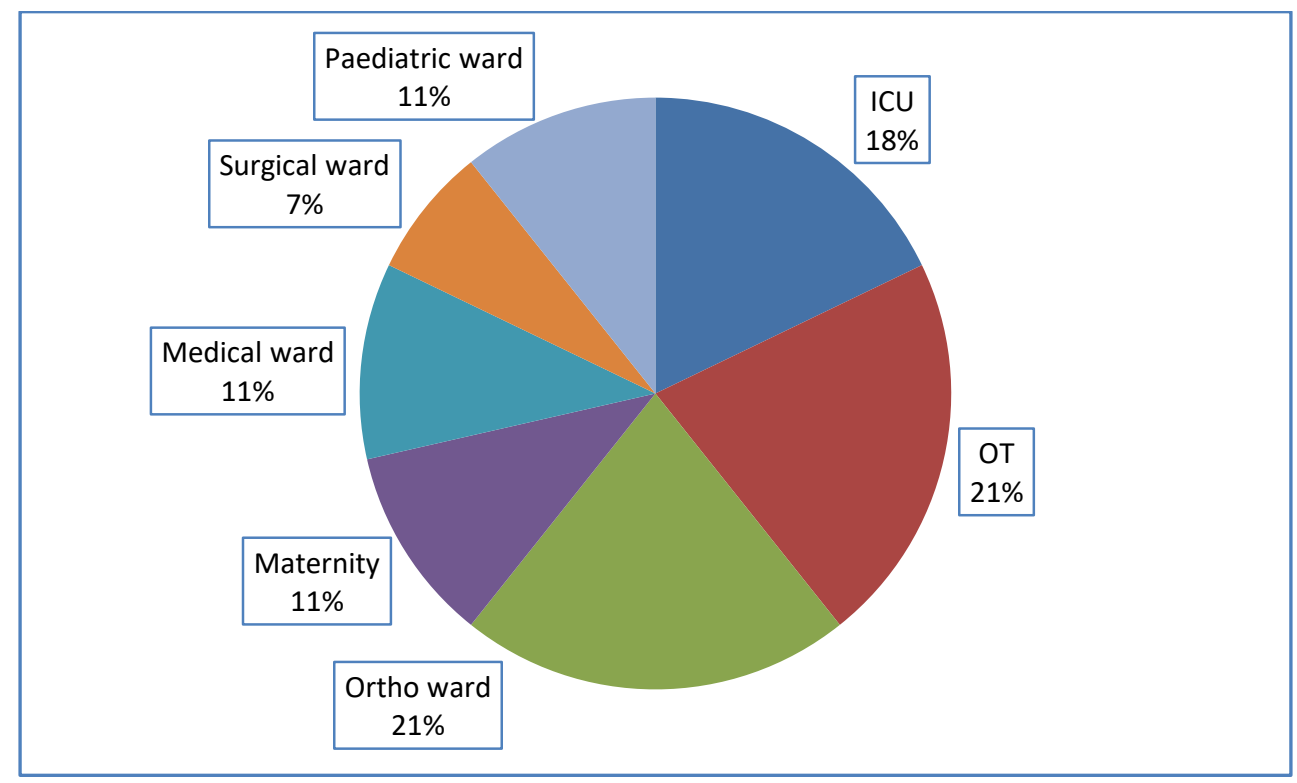

Figure 1. Prevalence of low back pain according to ward

Table 1. Distribution of respondents towards alleviating LBP $(\mathrm{N}=50)$

\begin{tabular}{llcc}
\hline Sn & Responses & frequency & percentage \\
\hline 1 & Use of correct body mechanics & 18 & 36 \\
2 & Addition of staffs in ward & 6 & 12 \\
3 & Less work load & 8 & 16 \\
4 & Timely rest & 5 & 10 \\
5 & Avoid prolong standing & 7 & 14 \\
6 & Use of pain relief medicines & 2 & 4 \\
7 & Use of advanced medical equipment & 1 & 2 \\
8 & Good working environment & 1 & 2 \\
9 & Find out other cause of back pain & 1 & 2 \\
10 & Weight control/reduction & 1 & 2 \\
\hline
\end{tabular}

Table 1 illustrates the factors that were indicated as being responsible to alleviate for the development of LBP by the participants. These included use of correct body mechanics (18; $36 \%)$, less work load $(8 ; 16 \%)$, avoid prolong standing $(7 ; 14 \%)$ and addition of staff in the ward $(6 ; 12 \%)$. The majority of back pain ranges from mild to moderate pain (Table 1$)$. The pain as complained by nurses is usually tolerable with mild pain killer more than half of their sufferers were self-medicated with over-the-counter drugs. This explains the reasons for the low rate of doctor consultations and low proportion on prescribed medication. This result was also in agreement with a study by Cilliers and Maart (2013) who revealed that only negligible numbers of nurses chose to medicate after the initial LBP incident but contradict in the rate of doctor consultation (3.57\%) among those with low back pain is much lower in this study. 


\section{Conclusion}

The findings of this study show that LBP is prevalent among the nurses. The majority of nurses, regardless of where they work at present, experience LBP on a regular basis. LBP is a serious problem amongst the nurses at the hospital, but no proactive approach is taken in order to address this problem. Policy guidelines and a comprehensive prevention and treatment programme need to be designed and implemented to address this issue.

\section{References}

Amany, M., Abou El-Soud, Amany R El-Najjar, Nada A El-Fattah \& Aida A Hassan 2014. Prevalence of low back pain in working nurses in Zagazig University Hospitals. An Epidemiological Study 41(3): 109-115.

Attarchi, M., S. Raeisi, M. Namvar \& M. Golabadi 2014. Association between shift working and musculoskeletal symptoms among nursing personnel. Iran J Nurs Midwifery Res. 19(3): 309314. PMCID: PMC4061634

Cilliers, L. \& S. Maart 2013. Attitudes, knowledge and treatment of low back pain amongst nurses in the Eastern Cape, South Africa. Afr J Prm Health Care Fam Med. 5(1), Art. \#535, 8 pages. http:// dx.doi.org/10.4102/phcfm. v5i1.535.

Rahman, M.A., J. Rozy, I. Halim, M. Jamsiah \& A.S. Shamsul 2008. Prevalence of back pain among nurses working in Government Health Clinics and Hospital in Port Dickson, Malaysia. Journal of Community Health 14(2):-11-18.

Sikiru, L. \& H. Shmaila 2009. Prevalence and risk factors of low back pain among nurses in Africa: Nigerian and Ethiopian specialized hospitals survey study. East Afr J Public Health 6(1): 225.

Smedley, J., F. Trevelyan, H. Inskip, P. Buckle, C. Cooper \& D. Coggon 2003. Impact of ergonomic intervention on back pain among nurses. Scand J Work Environ Health 29(2): 117-123 doi:10.5271/sjweh.713

Vidya, V.P., V.F. D’Souza, T.O. Vinyamol \& Vivian Ma 2014. The knowledge and practice of bodyemchanics among staff nurses: descriptive co relational study. American International Journal of Research in Humanities, Arts and Social Sciences AIJRHASS pp. 14-643. www.iasir.net

Yassi, A., J. Khokhar, R. Tate, J. Cooper, C. Snow \& S. Vallentyne 1995. The epidemiology of back injuries in nurses at a large Canadian tertiary care hospital: implications for prevention. Occup Med (Lond) 45(4): 215-20.

Yin bing, Y. 2001. A study of work stress, patient handling activities and the risk of low back pain among nurses in Hong Kong. Journal of Advanced Nursing 36(6): 794-804. doi: 10.1046/j.1365-2648.2001.02037.x 